
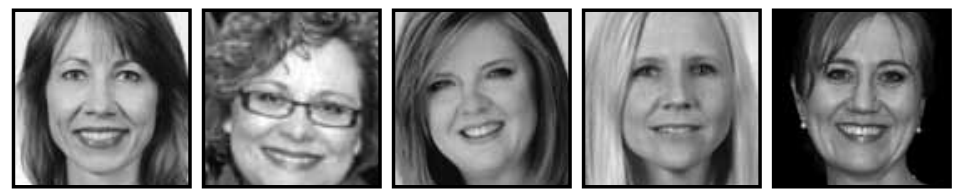

\title{
License to Drive, License to Learn. Promoting Policy for Safe and Innovative Social Networking Use Schools
}

\author{
Teresa S. Foulger, Arizona State University \\ Ann D. Ewbank, Arizona State University \\ Heather L. Carter, Arizona State University \\ Pamela Reicks, Washington Elementary School District \\ Sunshine Darby, Dysart Unified School District
}

\begin{abstract}
This article advocates for the use of social networking tools as a way for teachers and students to enrich learning possibilities. While some school systems resist the use of social networking tools for learning purposes, others are moving forward with this idea. There is clearly a need for policy that will guide the decision-making and pedagogical orientations of school administrators and teachers. The authors suggest that policy surrounding the use of social networking tools such as Facebook, Twitter, and Instagram take into account two equally important objectives: innovation and safety. They propose that educational institutions create policies that empower learners to strengthen their communication skills, expand global perspectives, and create unlimited networking capacity.
\end{abstract}

\section{Introduction}

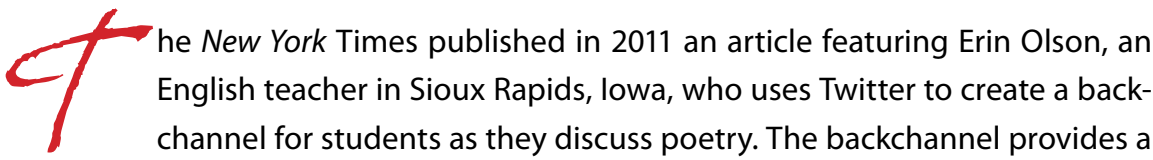


constant stream of analysis via short tweets of a poem called, "To the Lady," which flows through Twitter while students simultaneously discuss the poem in class. Ms. Olsen says the use of Twitter creates an encouraging environment for students who are normally reluctant to speak up in class to engage in discussion (Gabriel, 2011).

Don Featherstone, an English teacher at E. C. Drury High School in Milton, Ontario, Canada, has his students create a Facebook profile based on a character in a book. Mr. Featherstone directs the students to "fill in the Facebook page as if you are the character. Include pictures, likes, dislikes, etc., maybe links or lists that apply. Explore the platform, but make everything suitable for that character!" This approach allows students to analyze literary characters in a way that is both authentic and suited to students' technology-savvy existence (Featherstone, 2009).

Teachers who use social networking tools do so because they offer their students a medium through which to meaningfully interact with each other as well as with users beyond their classroom walls. In essence, these teachers expand the concept of classroom collaboration to include (potentially) anyone with Internet connectivity. For example, teachers and students can follow someone running for a local or national political office via their Twitter feed or Facebook profile and track public opinion shifts; ask students to interact with a National Geographic photographer whose work is posted in Instagram; or share local events, interests, and political events via a Tumblr blog, and discuss differences in cultural norms and values with children in classrooms across the world who read their blog.

Many students use social networking tools as a part of their everyday lives. This level of familiarity makes Facebook, Twitter, and other social networking tools convenient for teachers to adopt in the classroom. Because students understand this power, and even the potential drawbacks, they can potentially do much of the innovating in terms of facilitating academic exchanges. By contrast, students who are not allowed classroom access to these powerful tools may feel (and be) shortchanged by limitations to engagement with the world outside the classroom.

Social networking tools offer the potential to support knowledge creation through collaborative interactions by anyone, from anywhere, as long as they have access. These tools are open-ended and offer great power to educators; we cannot predict their future uses because we are still in the process of technological innovation (Hall \& Hord, 2001). But we do claim that schoolchildren's access to a world of information (both reliable and not reliable), and to other people, is far greater today than it was a few short years ago. 
As remarkable as these tools are, the outside world sees a dark side to increased access. Facebook has received media coverage documenting potential dangers (Carter, Foulger, \& Ewbank, 2008). When teachers use Facebook with their students, they are encouraged to err on the side of caution. For example, the Lake County School District in Florida created "Guidelines for Employee Use of Social Media Networks" recommending that employees' blogs, Facebook profiles, and websites be "G-rated" at all times (Huffington Post, 2012).

Some policy makers, school administrators, and parents express concerns about teacher-student interaction online. Fountain Hills, Arizona superintendent Bill Myhr believes that teachers who "friend" students online cross ethical boundaries (Woodberry, 2011). Evidenced by many stories that appear about teachers and social media use, media outlets are quick to expose those teachers who have been reprimanded for the ways in which they negatively use social networking tools.

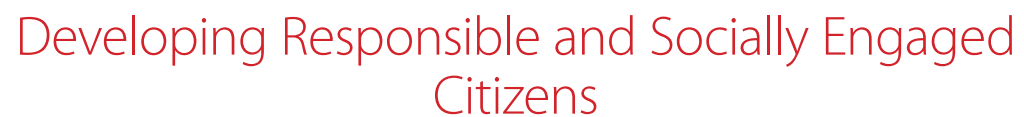

Teachers and students need to do what they do best-teach and learn. The authors of this article represent the perspectives of a State Legislator, university professor and researcher for teacher education, school board member, and school district professional developer. We believe that there is great potential in exploring the use of social networking tools for educational purposes. The goal of our advocacy is to facilitate the development of a culture of learning by expanding the reach of children and teachers beyond the four walls of the traditional classroom (Ewbank, Foulger, \& Carter, 2010). We believe that school leaders can figure out how to use social networking tools to empower learners to strengthen their communication skills, expand global perspectives, and create unlimited networking capacity. We support our position through John Dewey's thoughts about technology and its role in society.

Dewey wrote extensively about technology in his seminal 1915 work, School and Society. In the 19th century, when mechanical technology was necessary to accomplish daily tasks, it was important for individuals to have the knowledge and skills necessary to be safe and effective technology users, including an understanding of how technology functions, a notion that Waddington (2010) calls "technological transparency." An example of technological transparency is found in Dewey's Laboratory School: 
[The student] followed the wool from the sheep to the rug, patiently contriving his own spindle, his own dye, his own loom.... He saw that while successive inventions of machines have led to the eventual betterment of social life, the immediate results have often been at the bitter cost of the discarded hand-worker whose plight illustrates an ever-present social problem caused by technological advance. (Mayhew \& Edwards, 1936, p. 314)

Technological transparency provided citizens with agency and power because they understood the mechanisms important to society. Dewey's vision was that individuals would advocate for themselves as the industrial age progressed.

Dewey (1915) made a distinction between open and closed technology. Closed technological tools are those that users do not understand how the tools function, nor do they have influence on their design and evolution. By contrast, open tools are those that are more transparent to end users, because they understand the inner workings of the tool and its overall function. Dewey suggested society should privilege open tools because "citizens would be able to make technologies work for them, rather than simply being shaped by prevailing technologies" (Shaikh et al., 2012 , p. 94). We posit that those using open tools are more likely to create innovation, because they have some control over the furtherance and development of the tool, and the results are useful for themselves as well as for others. It follows logically that open technology has the power to shape society rapidly, because the original creator does not maintain control over any modifications of the tools.

This line of thinking about the power of open technologies can be applied to Web 2.0 tools, as a form of modern-day tool associated with our knowledge-driven society (Shaikh et al., 2012). Although the interface of Web 2.0 tools cannot be modified by the user, they do allow users to create content, control their interactions, and socially engage with one another to make larger contributions. For example, Facebook users are afforded the possibility of agency, variety, and invention because decisions about content are theirs, and inspiration from one another matters in this medium.

\section{Amy Hestir Protection Act in Missouri}

State legislators in Missouri recently tried to stymie the idea of students using open technology in the classroom by passing the Amy Hestir Student Protection Act, a law that went into effect in the state of Missouri on August 28, 2011 (Gottlieb, 
2011a). Named after a now 40-year-old-woman who was sexually abused by her art teacher when she was in junior high, the law was repealed less than one month after it was instated. The appealed law originally set out to require each school district to develop a written teacher-student communication policy, including a plan for in-person and online interactions. The law specified that any work-related social media website established by a teacher was to be completely viewable to the public, including school administrators, parents, and guardians. Furthermore, teachers were not allowed to engage in private, online social media communication (such as private messaging, or the "friends only" function in Facebook) with current or former students who were under 18 years of age. In summary, the law prohibited several types of teacher-student communication via social media.

The intent of the law was to protect minors against inappropriate adult interactions. However, the Missouri Teachers Association and American Civil Liberties Union identified several unintended consequences. According to the law, any communication about private matters between teachers and students would be made public, a violation of the U.S. Family Educational Rights and Privacy Act (FERPA) law of 1974. An additional problem with the law was that web-based tools constantly change without notice. This puts educators in a situation whereby they never know if new features or tools are "safe" or not.

In less than one month a series of lawsuits questioned the law's constitutionality. Missouri Governor Jay Nixon called for a special legislative session and the Amy Hestir Student Protection Act was repealed September 23, 2011 with the justification, "In a digital world, we must recognize that social media can be an important tool for teaching and learning" (Gottlieb, 2011b). This reminds us how difficult it is to create timeless legislation surrounding technology. Useful policy will need to embrace the positive impact that technology tools can have in education while still promoting safety, innovation, and accountability.

\section{Laws and Policies Already Adequate, Yet Districts Take Traditional Approach}

Many laws and policies are already in place that support these goals. For example, the 2000 U.S. Children's Internet Protection Act (CIPA) established that all public educational systems in the United States that are recipients of E-rate funding, special grants, and other federal aid in support of technology integration, use 
filtering software to protect students from potentially inappropriate content. A U.S. federal policy implemented in August 2011 requires that public schools and libraries that are E-rate recipients assure their Internet policies are updated to include provisions for teaching students safe use of social networking tools as well as awareness of cyber-bullying. Additionally, about half of the states in the U.S. have adopted laws that mandate filtering systems in publicly funded schools and libraries in order to prevent student access to questionable material (National Council of State Legislatures, 2012). Canada, however, has used existing law to regulate obscene content on the Internet, such as the Canadian Criminal Code (OpenNet Initiative, 2012).

Similarly, most school districts have acceptable use policies that both employees and students/parents sign before Internet use can be granted through school networks. When parents approve their child's Internet use at school, they affirm that they understand the benefits as well as the risks of students using the Internet. These policies promise parents that teachers will conduct training, provide direction, and supervise students who use Internet-based tools while in their care. Those school districts that have kept up to date on technological advancements have added provisions for social networking tools to their acceptable use policies. If a student does not have parental permission to use the Internet, teachers must meet educational objectives in other ways.

Additionally, social networking tools provide protection through their policies. For example, Facebook policy mandates that users must be thirteen years of age, and users between the age of 13 and 18 do not appear in public searches. All users must agree that Facebook "reserves the right to add special protections for minors (such as to provide them with an age-appropriate experience) and places restrictions on the ability of adults to share and connect with minors." Along those same lines Facebook provides a "Report Abuse" link and requests that offensive posts be reported (Facebook, 2011).

\section{Social Media: A License to Drive, A License to Learn}

Learning to drive a car is comparable in certain aspects to learning to use social networking tools. The vehicle (or social media) is a powerful tool that improves numerous capabilities. Over time, children gain more freedom as they become more effective with driving. This developmental perspective might be a useful approach to policy development surrounding social networking use in education. 


\section{Young Children-Teacher Navigation}

When they are very young, children are passengers in cars that are driven by adults. Similarly, at this age, we suggest policy that promotes the use of social networks "driven" by teachers, with students' educational needs in mind.

For example, Union County Public Schools (North Carolina, USA) teacher Liz Benavides created a virtual pen pal program with Saudi Arabia via Skype. Elementary-age children communicated through Liz, with Prince Khalid Bin Alwaleed Bin Tala (Franco, 2011). Social media facilitated a rapid, convenient, timely, and comprehensive exchange of information.

\section{Tweens and Young Teens-Teacher Supervision}

When children reach their teenage years, they can earn a learner's permit and are granted permission to drive, but under the direct supervision of an adult who accompanies them in the vehicle. The adult in charge is accountable, to a great extent, to provide direct "sideline coaching" during that teen's use of any vehicle. Similarly, as teens show responsibility in the use of the Internet, it is appropriate that policy mandates teacher supervision in class as well as in online environments, to assure students make good decisions through a "sideline coaching" model about the use of social networking tools.

For example, Ann Flynn, Director of Technology for the National School Board Association, reports that a school in Cleveland, Ohio, USA, has turned the traditional book report into a social media experience. Students post their book report online, and parents, teachers, and other students read and comment on the report (Sorrentino, 2012). In this case, the teacher was responsible for guiding studentsjust as adults are required to be in the car of teenagers to assure safe circumstances, and not joyriding or racing.

\section{Full Privileges for Qualified Students}

Then, when teens have proven they know the rules of the road and can successfully and safely navigate the driving system, including handling unexpected behaviors from other drivers, they are granted complete freedom to drive on their own. With this level of independence, parents need to be able to trust these teens to make responsible decisions. This cannot happen without prior experience. Similarly, in the education domain, as students are granted more freedom to use social networking tools for learning, policy should hold students accountable for their 
behavior, including keeping on topic, conducting themselves professionally, and treating others with respect. Appropriate and firm consequences will be necessary for this level of freedom.

For example, Buffy Hamilton, high school librarian in Canton, Georgia, USA, discovered recently that the blogging platform Tumblr.com was blocked by the Internet filter at her school. She requested access, outlining a number of educational uses, including "crowdsourcing" favorite book quotes and book covers. Hamilton stated,

Tumblr has been super hot with our teens for blogging in the last six months or so, and I would like to utilize Tumblr for digital composition and reflective thinking since it so easily allows users to post content in many formats/multimedia. I especially like how Tumblr lends itself to formal as well as informal networked learning and dovetails beautifully with a participatory stance on learning and librarianship (2011).

\section{Future Directions: Promoting Safety, Innovation, and Accountability}

While the specific example of the Missouri law ultimately failed as policy, provinces and states may consider adopting a refined version of this law, one that would protect students from the problems associated with social networking without inadvertently prohibiting students and teachers from using any social networking tool, even tools specific to education such as Edmodo, TeacherTube, Google Sites, and the Google Suite (Docs, Presentations, and Forms).

The best educational policy is one that allows students opportunities to learn in ways that are aligned with the 21 st century workplace. Figuring out solutions to these issues will require a collective intelligence of all educational stakeholders and the concerted efforts of many outside the school systems.

The following are guidelines for policy development aligned with this perspective:

1) Provide safe environments for the use of social networking tools by students, for educational purposes. 
2) Embrace teachers' creativity by granting them the necessary freedom to think innovatively, (within the boundaries of educational needs) as they explore the possibilities of social networking tools.

3) Hold teachers accountable to train, guide, supervise, and discipline students during the educational use of social networking tools while at school.

This year's kindergarten class will graduate from high school in 2025. With this long-range goal in mind, educators should ask themselves, "What will 2025 look like?" Technology is advancing so rapidly that a prediction of this sort is difficult. Yet, it is our duty to prepare them. As educational technology advocates, we challenge educators and policy makers to work toward achieving this goal.

\section{References}

Carter, H. L., Foulger, T. S., \& Ewbank. A. D. (2008). Have you Googled your teacher lately? Teachers' use of social networking sites. Phi Delta Kappan, 89(9), 681-685.

Dewey, J. (1915). The school and society (2nd edition). Chicago: University of Chicago Press.

Ewbank, A. D., Foulger, T. S., \& Carter, H. C. (2010, September). What can Colleges of Education learn from Red Bull and Starbucks? Social networking and the changing face of teacher education. Phi Delta Kappan.

Facebook. (2011). Statement of rights and responsibilities. Retrieved from https:// www.facebook.com/legal/terms

Featherstone, D. (2009). Unit project: Facebook a character! Retrieved from http:// mrfeatherstone.blogspot.com/2009/04/ unit-project-facebook-character.html

Franco, V. (2011). Children connecting the world. Union County Weekly. Retrieved from http://www.unioncountyweekly.com /arts_entertainment/2011/06/children -connecting-the-world/
Gabriel, T. (2011a). Speaking up in class, silently, using social media. The New York Times. Retrieved from http://www.nytimes.com /2011/05/13/education/13social.html? pagewanted=all

Gottlieb, J. (2011a). Amy Hestir Student Protection Act: Protecting students or stifling teachers? Social Media Law News. Retrieved from http:// socialmedialawnews.com/2011/08/19/amyhestir-student-protection-act-protecting-stu dents-or-stifling-teachers/

Gottlieb, J. (2011b). Missouri repeals Facebook ban. Social Media Law News. Retrieved from http://socialmedialawnews.com/2011 /09/23/missouri-repeals-facebook-ban/

Hall, G. E., \& Hord, S. M. (2001). Implementing change: Patterns, principles, and potholes. Boston: Allyn and Bacon.

Hamilton, B. (2011). Tumblr is more than porn: Tumblr for inviting participation and conversations for learning. The Unquiet Librarian. Retrieved from http://theunquietlibrarian.wordpress.com/2011/08/06/ tumblr-is-more-than-porn-tumblr-forinviting-participation-and-conversa tions-for-learning/ 
The Huffington Post. (2012). "School District Sets Guidelines on Teacher Social Networking." Retrieved from http://www. huffingtonpost.com/2011/04/10/teachers -social-networking_n_846340.html

Mayhew, K.C., \& Edwards, A. (1936). The Dewey school. Chicago: D. Appleton Century.

National Council of State Legislatures. (2012). Laws Relating to Filtering, Blocking and Usage Policies in Schools and Libraries. Retrieved from http://www.ncsl.org/issues-research /telecom/state-internet-filtering-laws. aspx\#states

OpenNet Initiative. (2012). United States and Canada. Retrieved from http://opennet. net/research/regions/namerica

Shaikh, K., Venkatesh, V., Thomas, T., Urbaniak, K., Gallant, T., Waddington, D. et al. (2012). Technological transparency in the age of Web 2.0: A case study of interactions in Internet-based forums. In Pontes, E., Silva, A. Guelfi, A., \& Kofuji, S. T., (Eds.). Methodologies, tools and new developments for E-learning. Retrieved from http://cdn. intechopen.com/pdfs/27921//nTech-Technological_transparency_in_the_age_ of_web_2_0_a_case_study_of_interactions_in_internet_based_forums.pdf
Sorrentino, J. (2012). Online education: Study shows social networking a boon for education. Education.com. Retrieved from http://www.education.com/magazine/ article/online_ed/

Waddington, D. I. (2010). Scientific self-defense: Transforming Dewey's idea of technological transparency. Educational Theory, 60(5), 621-638. doi:10.1111/j.1741-5446. 2010.00380.x

Woodberry, J.(2011)“Facebookfriendships between students, teachers a concern." The Arizona Republic. Retrieved from http://www.azcen tral.com/news/articles/20110814facebookteachers-students.html

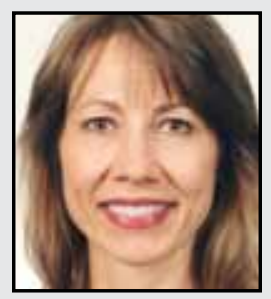

Teresa S. Foulger is an Associate Professor in the Mary Lou Fulton Teachers College at Arizona State University, USA. Her research interests include collaboration, leadership, and innovation in technology-rich educational contexts. She teaches educational technology courses to preservice teachers, and action research, innovation, and mixed methods to doctoral students. She serves as the President of the Teacher Education Special Interest Group of the International Society for Technology in Education (ISTE). 


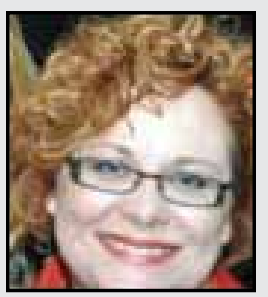

Ann D. Ewbank is a Clinical Associate Professor in the Mary Lou Fulton Teachers College at Arizona State University, USA. She is a former middle school and university librarian. Her research interests include information literacy. She believes that open access to information provides optimal learning experiences.

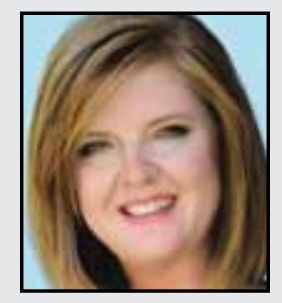

Heather L. Carter is a Clinical Associate Professor in the Mary Lou Fulton Teachers College at Arizona State University where she teaches educational technology courses to preservice teachers. Carter also serves in the Arizona legislature as a State Representative. She is an advocate for education and seeks to develop and refine policies that improve educational systems.

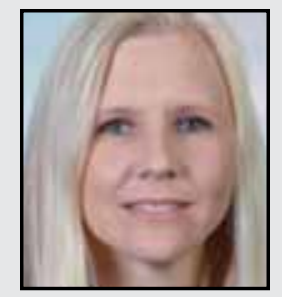

Pamela Reicks is a 7th grade Language Arts Teacher in Phoenix, Arizona, USA. She uses innovative technologies to support her students' classroom experiences. She also serves as a Governing Board Member in the Glendale Union High School District in Phoenix, and is interested in developing policies that support teacher innovation and furthering appropriate uses of social media for learning.

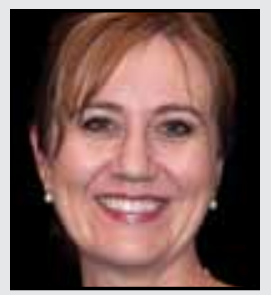

Sunshine Darby is the Technology Training Supervisor for the Dysart Unified School District in Surprise, Arizona. She also serves as a governing board member for the Arizona Technology in Education Association. Sunshine has 8 years of experience teaching middle school science and 7 years supporting teachers to use technology. She has taught technology integration courses to pre-service teachers at Arizona State University and her district recently hosted the National School Board Association Technology Site visit. 